\title{
REPRESENTACIONES SOCIALES, PERCEPCIONES E IMAGINARIOS DE JÓVENES ECUATORIANOS ARTESANOS/INDÍGENAS Y ARTISTAS/ESTUDIANTES, INMIGRANTES EN FRANCIA
}

\author{
MARYSOL PATIÑO SÁNCHEZ
}

CESPLA. Universidad de Cuenca (Ecuador).

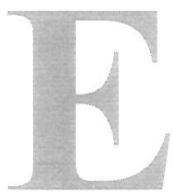

\section{RESUMEN}

n este trabajo se estudió cómo los jóvenes ecuatorianos imaginan la migración internacional, el país de destino antes de migrar, cuáles son las motivaciones o razones que se derivan de esos imaginarios y qué los induce a tomar la decisión de viajar al exterior; cómo estas imágenes han evolucionado desde que tomaron la decisión de viajar hasta su llegada e inserción en el país de destino; cuáles son las representaciones sociales que tienen sobre el ser estudiante o trabajador inmigrante en Francia; cuáles son las imágenes que tienen de sí mismos; cómo construyen o reconstruyen su identidad a partir de la migración; cuáles son sus relaciones familiares y sociales; cómo han variado sus prácticas culturales, proyectos de vida y de desarrollo o realización personal al insertarse en la sociedad francesa, cómo han cambiado sus actividades laborales y educativas antes y después de migrar.

Palabras clave: Imaginarios, migrantes ecuatorianos en Francia, Identidad, redes.

\section{INTRODUCCIÓN}

La finalidad del presente estudio fue conocer en profundidad las representaciones sociales, imaginarios y percepciones sobre la migración internacional de los jóvenes inmigrantes en Francia, específicamente de los que habitan en las ciudades de Metz, Nancy, París y Nantes. 
Se trata de una investigación cualitativa cuyo interés fue conocer cómo se producen y reproducen los procesos de la migración internacional en el país de destino, a través de un análisis del discurso de los jóvenes inmigrantes ecuatorianos, de sus representaciones y prácticas sociales a partir del hecho migratorio, hito muy importante en su historia de vida. Para ello se emplearon las técnicas de la entrevista en profundidad, relatos de vida y la observación participante.

Se entrevistó a veinte jóvenes en total, diez de ellos son hombres y mujeres indígenas ${ }^{1}$ ecuatorianos que viven en este país europeo, comercializando sus artesanías o formando parte de grupos de música folklórica, la mayoría de ellos están regularizados, salvo una pareja que aún no ha arreglado sus papeles, a pesar de que su hija nació en Francia. Por otro lado se entrevistó a diez jóvenes mestizos, artistas que estudian y trabajan en Francia, todos tienen la visa de estudiante, excepto dos de ellos que tienen la nacionalidad francesa por ser hijos de padre francés y madre ecuatoriana. Las edades de estos jóvenes son de 18 a 25 años.

Se realizó también entrevistas a informantes claves como la Cónsul de Ecuador en Francia para conocer sobre la situación general socioeconómica y demográfica de la población ecuatoriana y a inmigrantes ecuatorianos familiares y amigos de los jóvenes que viven más de 15 años en Francia.

La limitación más importante que se debió enfrentar en el desarrollo de la investigación, que a su vez constituyó un reto, fue la inexistencia de estudios sobre la población inmigrante ecuatoriana en Francia (en el caso de que existiesen no son lo suficientemente difundidos), debido a que numéricamente esta población no es significativamente representativa en relación a otras comunidades de inmigrantes en Francia.

En una primera parte de este artículo se expondrán algunas reflexiones previas sobre las categorías conceptuales de imaginarios, representaciones sociales, vida cotidiana y prácticas culturales; sobre la metodología empleada; se expondrá sobre una breve reseña histórica de los flujos de la población ecuatoriana que ha inmigrado a Francia y finalmente se describirán sobre algunas características sociodemográficas de los ecuatorianos que actualmente viven en este país europeo.

En una segunda parte se describe y analiza la información recogida en el trabajo de campo realizado en Francia, sobre los imaginarios,

1 Se los identifica así, porque ellos se autodefinían como tales. En su mayoría los jóvenes entrevistados utilizaban la vestimenta típica de los grupos étnicos otavaleños y salasacas. Aunque sus nombres eran hispanos hablaban entre ellos en kichwa, con los demás ecuatorianos y latinos hablaban en español y empleaban algunas palabras en francés principalmente las que requerían para vender sus artesanías o productos artísticos como los discos compactos, como se pudo conocer en la observación participante. 
representaciones sociales, percepciones de los jóvenes ecuatorianos en Francia antes y después del hecho migratorio

\section{LOS CONCEPTOS DE REPRESENTACIONES SOCIALES, IMAGINARIOS, VIDA COTIDIANA Y PRÁCTICAS CULTU- RALES}

Para develar las expresiones culturales y subjetivas de la migración internacional, requerimos por un lado conocer sobre las significaciones o representaciones sociales de la población inmigrante en el país de destino pero también sobre sus prácticas sociales.

Partimos del supuesto de que en las interacciones de la vida cotidiana los sujetos representan roles o papeles y por otro lado ofrecen conceptos e imágenes de sí mismos para lo cual necesitan ciertos referentes que les permiten actuar.

A estos referentes Goffman los llama "ciertos estándares de comportamiento: la recíproca accesibilidad regulada en los encuentros sociales es una accesibilidad para recibir y transmitir estos flujos de representaciones y comunicaciones que describen personajes y sus acciones" (citado por Wolf, 1988,66).

A estas significaciones de las acciones o los personajes, se las identifica como representaciones sociales. Consuelo Yánez Cossío las define como: "ideas que son utilizadas consciente o inconscientemente en la vida cotidiana. Es la manera de ver, entender, interpretar o concebir una realidad, no son un producto casual ni se encuentran aisladas" (1998:33)

Diversos autores suelen emplear indiscriminadamente o como sinónimos las categorías conceptuales de representaciones e imaginarios. Así, por ejemplo, Denise Jodelet, plantea que las representaciones sociales son un conjunto de imágenes, significados o sistemas de referencias, se refiere a ellas no sólo como categorías conceptuales sino también como teorías que permiten explicar ciertos fenómenos sociales ${ }^{2}$.

En el caso de la presente investigación se considera que las representaciones sociales no son sólo imágenes sino también son interpretaciones de la realidad. Se argumenta que esta categoría conceptual además de la noción de imagen integra la de actitud, opinión, creencias, estereotipos, es decir, en este estudio el interés fue conocer cómo los

2 Para una mayor profundización sobre el planteamiento de Denise Jodelet se recomienda revisar su texto: La representación social: fenómenos, concepto, teoria. En Pensamiento y Vida social. Psicologia y Problemas sociales, de Serge Moscovici, pág. 472. 
sujetos protagonistas de los procesos migratorios plantean significados e interpretan la migración internacional, basándose en ciertos imaginarios.

Cabe recordar que los primeros estudios referidos a los imaginarios y representaciones sociales son los realizados por Durkheim, quien plantea el concepto de "conciencia colectiva". Estas categorías conceptuales aparecen en Sociología, sin embargo, permaneció olvidada por esta Ciencia por muchos años, hasta que la Psicología Social las recupera (especialmente la Psicología Infantil, entre estos autores se menciona a J. Piaget.). Posteriormente es empleada por todas las Ciencias Sociales, elaborándose una teoría sobre las representaciones sociales. Entre sus exponentes principales se menciona a Moscovici y Denise Jodelet.

En los estudios sobre la migración internacional, las investigaciones sobre los imaginarios y representaciones sociales son relativamente nuevos, sin embargo, han cobrado vital importancia, a partir de ellos ha surgido la construcción o elaboración de diversas categorías conceptuales.

En la construcción de los imaginarios confluyen dos tipos de factores, los objetivos y los subjetivos. Los primeros tienen que ver con los "elementos que se desprenden de la estructura en que el actor establece sus prácticas vitales. Constituyen los factores objetivos o condiciones materiales ya que son externos y no controlables por los individuos... Los subjetivos se construyen a partir de las aspiraciones, expectativas y valoraciones de este grupo humano" (Goicoechea, 2003, 9).

En el campo de las teorías culturales sobre las migraciones se define a los imaginarios como "construcciones culturales" que son inherentes a todos los emigrantes, en las cuales intervienen componentes racionales e irracionales, objetivos y subjetivos, reales e ideales presentes antes y después del hecho migratorio ${ }^{3}$.

Los imaginarios sociales, sin desligarlos de sus relaciones con lo histórico y lo físico, también están influenciados por las visiones fantasiosas que también contribuyen directa o indirectamente, consciente o inconscientemente a la reproducción de los procesos migratorios.

Las representaciones sociales e imaginarios que los jóvenes construyen en el país de origen (a partir de la información que reciben a través de las cadenas y/o redes de sus familiares en el exterior) al confrontarse con lo real, es decir, con lo que posteriormente viven en el pais de destino, se convierten en algunos casos, en desilusión o frustración y en

3 Uno de los autores que más ha profundizado sobre estas teorías culturales y que define a cstos imaginarios como construcciones culturales es el investigador peruano Teófilo Altamirano. 
otros en la concreción de un sueño o aspiración. De cualquier forma estos imaginarios sobre la migración internacional son determinantes en su proyecto de vida.

En esta investigación se pretendió, por lo tanto, desentrañar cuáles son las imágenes de estos jóvenes sobre el proceso migratorio basadas en hechos reales, visualmente registradas o sentidas y también las fundamentadas en rumores y/o visiones fantasiosas, sueños e ideales construidos a partir de los microprocesos de la vida cotidiana y/o legados históricamente.

Se argumenta que, partiendo de un análisis de los micro-escenarios, se pueden determinar las formas de reproducción particulares, que a su vez posibilitan un análisis de la reproducción social reflejada en las macro-escenas. Los estudios sobre la vida cotidiana son necesarios para entender no únicamente la cultura, sino los modos, relaciones y procesos sociales, en este caso, los referidos a la migración internacional.

Se considera la vida cotidiana como los microprocesos donde se producen y reproducen las relaciones sociales; constituyen el conjunto de prácticas y representaciones que reflejan una cultura o modo particular de ver el mundo y de actuar en él.

En conclusión el presente estudio se basa en los postulados de la Sociología de la vida cotidiana, es decir, su objeto de estudio se centra en estos microprocesos que implican rutinas, reiteraciones y discursos compartidos entre los jóvenes inmigrantes ecuatorianos en Francia, para conocer sobre cómo ellos se integran a los nuevos grupos de pertenencia o a los nuevos escenarios en las sociedades de destino, sobre cómo configuran, construyen y reconstruyen su identidad, cómo surgen nuevos símbolos, prácticas culturales y nuevas formas de imaginar, de entender y de interactuar o relacionarse con los otros.

\section{ALGUNAS REFLEXIONES METODOLÓGICAS}

Como afirma Luis Enrique Alonso "los universos intersubjetivos, en los que el sentido y la significación de las cosas -su valor social- es el producto de un proceso comunicativo donde existen y se producen códigos que articulan y unifican la lectura de la realidad y por tanto, la construcción de la realidad misma. Construcción que se realiza justamente a partir de la creación, objetivación y legitimación de universo simbólicos, o si se requiere de imaginarios sociales" (Alonso, 1998, 216).

Para conocer sobre los imaginarios, percepciones y representaciones sociales es necesario emplear la metodología de investigación cualita- 
tiva y en particular el Método Biográfico, que en los estudios sobre la migración internacional ha adquirido mucha importancia, sin embargo, existe un uso indiscriminado de los términos que se derivan de este método, surgiendo una diversidad de términos: historias de vida, relatos de vida, biografía, autobiografía.

Estas significaciones han variado en las diferentes Escuelas Sociológicas, a lo largo de los años, desde que apareció este método en las CCSS en 1920, en la Escuela de Chicago, hasta la aparición de la "histoire de vie" (historia de vida) en la Sociología francesa.

Sin profundizar en estos debates y diferencias, es importante resaltar que la importancia del método biográfico radica en que "no se limita solamente a la recogida descontextualizada de los relatos de vida sino que construye su análisis de las trayectorias individuales en el marco de los grupos primarios de referencia (grupo doméstico, parentela, banda o gang, minoría étnica). (Juan José Pujadas, 1992, 12).

Desde sus inicios, este método fue de mucha utilidad para abordar la migración internacional, así, por ejemplo, se menciona los estudios realizados por J. Landesco (hijo de obrero italiano) y F. Thrasher, quienes basándose en las autobiografías realizan investigaciones sobre las bandas italianas presentes en EEUU en los años 30. El investigador Jean Peneff afirma que estos estudios lucharon contra los estereotipos dominantes que consideran a estas bandas como el resultado de una tendencia perversa de los grupos de italianos o polacos $(1990,54-55)$.

En conclusión, el método biográfico permite obtener información sobre el desarrollo de la vida de una persona y sobre cómo un individuo crea y refleja su realidad individual y social. En la presente investigación más que historias de vida, se emplearon relatos de vida, que sirvieron de mucha utilidad para conocer sobre las trayectorias individuales, familiares y sociales de los jóvenes a partir del hecho migratorio, uno de los hitos más importantes en su historia de vida.

Estos relatos de vida fueron reconstruidos a través de las entrevistas en profundidad realizadas a los jóvenes, el empleo del foto-lenguaje, los testimonios e historias de vida de algunos familiares o amigos de los jóvenes (en los casos en los que fue posible hacerlo) que viven muchos años en Francia. Además se utilizó la observación participante para conocer sobre las prácticas cotidianas de los jóvenes en su trabajo, en la universidad, en las calles, trenes, ferias, festivales o lugares de trabajo, es decir, en los escenarios cotidianos donde los jóvenes interactúan con sus pares, con sus amigos latinos o franceses, en los departamentos donde residen, o en algunos lugares recreativos como discotecas y bares. 
En conclusión, el empleo de la metodología cualitativa permitió conocer en profundidad los rastros que la migración marca, impone o determina en la vida cotidiana de los jóvenes, en sus relaciones sociales, en la inserción en el mercado de trabajo y en sus prácticas culturales.

\section{BREVE RESEÑA HISTÓRICA DE LA POBLACIÓN ECUATO- RIANA QUE HA INMIGRADO A FRANCIA}

Investigando sobre algunos antecedentes históricos referidos a los primeros grupos de ecuatorianos que han inmigrado a Francia, se conoció que en una primera fase (1920 a 1950) los inmigrantes ecuatorianos que llegaron a este país, al igual que a otros países europeos, pertenecían a la clase oligárquica, terrateniente política y académica.

"Europa del Oeste aparece como la región de mayor atracción, en particular entre las décadas de 1920-1930. La revolución industrial y la herencia cultural de la nobleza y las clases sociales tenían enorme influencia en la sociedad y cultura ecuatoriana. La dependencia no solamente en la tecnología, la economía sino en las artes, permitió que los ecuatorianos vivieran a la moda y los estilos de España, Inglaterra y Francia..." (Altamirano, 2004, 246).

Posteriormente, después de la segunda guerra mundial y principalmente a finales de la década del 50, cambia la preferencia por el país de destino, los ecuatorianos optan por emigrar hacia EEUU, los sectores de donde proviene la población emigrante también se diversifica, emigrando hacia este país norteamericano, no solamente grupos vinculados al poder y oligarquía, sino además empiezan a emigrar sectores de la clase media, especialmente profesionales, además de algunos trabajadores especializados en la industria textil, las construcciones civiles y los que trabajan en la transnacional estadounidense United Fruit.

En esta década también se produce el colapso de la comercialización de los sombreros de paja toquilla (conocidos en todo el mundo como el "Pánama hot"), principal producto de exportación de la provincia del Azuay, zona andina, al sur del país, lo que provocó que algunos exportadores de estas artesanías también emigraran fuera del país utilizando los contactos de los importadores de ese producto en EEUU.

Como consecuencia del cambio de país de destino, disminuye sustancialmente los flujos de población que emigra al Viejo Continente y entre ellos a Francia, es necesario indicar que en este país, históricamente los flujos de población ecuatoriana inmigrante no ha sido numerosa, lo que no ha sucedido con EEUU que por muchos años fue el país de destino preferido por los ecuatorianos, por las mayores posibilidades 
de empleo, de acceder a mejores salarios y posteriormente por las redes de familiares que se instalaron en este país y que han servido como una suerte de "polo de atracción".

Es importante tomar en cuenta estos antecedentes históricos y conocer cuáles son las imágenes y significaciones sobre los grupos de "pioneros"4 como los define Altamirano para entender cómo y por qué aún persisten en la población ecuatoriana, las imágenes y representaciones sociales de la migración a Francia como símbolo de éxito o de status principalmente académico y artístico, que persisten en la actualidad como se evidenció en el discurso de los jóvenes entrevistados en la presente investigación.

Así como también es interesante contrastar las diferentes imágenes y representaciones sociales presentes en la historia de las poblaciones receptoras de inmigrantes con las de los países de donde proviene esta población. Mientras en Ecuador históricamente se han elaborado y reelaborado representaciones sociales e imágenes sobre la migración a Francia como se dijo anteriormente como símbolo de status o prestigio académico y artístico. Al contrario en Francia, en general, las imágenes que históricamente la población tenía sobre los inmigrantes están más bien vinculadas a los grupos excluidos.

Milgram y Jodelet realizaron un estudio en 1976 sobre la imagen de París, sobre el conocimiento, elección o rechazo residencial, del tipo de población y actividad que se observan en sus barrios, identificaron un núcleo y cinturón histórico: "Antes que nada surge un núcleo central donde se cristaliza un fantasma primigenio, la cuna, las raíces de la ciudad, todo lo positivo se concentra en los barrios del nacimiento de la urbe. Luego, una corona hoy inexistente, el mur des fermiers généraux, demolido en 1859. Este último deja en la memoria colectiva la huella de un ordenamiento social, realizado por el barón Haussaman que implicó el desplazamiento de las capas populares hacia los límites de la periferia, estableciendo una segregación humana y residencial que aún está muy presente en las imágenes sociales del París actual... Es hacia el norte y el este que serán rechazados los pobres $y$, sobre todo, los inmigrantes de todo tipo"s.

4 El concepto de pioneros es utilizado además de Teofilo Altamirano por varios investigadores como por ejemplo Jokish Brad, (2001): Desde New York a Madrid: tendencias en la migración ecuatoriana; Martha Cecilia Ruiz en "Ni sueño, ni pesadilla: diversidad y paradojas en el proceso migratorio", pág. 96.

Para los fines de la presente investigación se define como pioneros a los primeros miembros del grupo familiar o del poblado en emigrar fuera del pais.

5 Citados por Denise Jodelet: La representación social: fenómenos, concepio y teoria, en Pensamiento y vida social, Psicologia Social y problemas sociales, págs.470-471 
Surgen aquí algunas preguntas: ¿esas imágenes del inmigrante aún persisten en Francia o han variado a lo largo de los años?, ¿cómo se reproduce en las nuevas generaciones ese discurso? Fernando Poce señala que "el perfil del migrante en Francia ha cambiado y cambia continuamente. Al momento actual los migrantes son jóvenes con algún diploma de enseñanza superior, mujeres educadas que buscan más independencia personal, niños y adolescentes -sus motivaciones no son muy claras, pero muchos huyen de guerras en Africa, elites científicas y culturales, jóvenes solteros con pocos estudios-" (Ponce, 2003, 39-40).

En relación a los antecedentes históricos referidos a los primeros grupos de indígenas que emigran a Europa y en particular a Francia se señala que los indígenas otavaleños están considerados como los primeros. David Kyle, basándose en los autores Collier y Buitrón, señala que "a finales de los 40 comerciantes otavaleños itinerantes comercializan textiles en todo el Ecuador y afuera". Afirma que a finales de los años 60 estos comerciantes tenían "colonias" importantes en el extranjero (Kyle, 2001, 96).

Hasta esos años la inmigración de los indígenas y ecuatorianos en general, a los países de Europa del Oeste no era significativa, comienza a expandirse a partir de la década de 1960-1970, sin embargo, los incrementos sustanciales se registran a partir de 1990. El inicio de esta expansión se debe a ciertas medidas adoptadas por las políticas migratorias de algunos Estados europeos que facilitan la inmigración de la población ecuatoriana, como por ejemplo el Estado español.

En el año 1982, empieza el estancamiento económico que enfrenta Ecuador y, con él, otro "contingente" de personas que emigran al exterior. En 1999 se agudiza la crisis y la emigración internacional de ecuatorianos es masiva, hasta convertirse en un fenómeno social de importantes dimensiones demográficas y sociológicas no sólo en Ecuador sino también en algunos países europeos, especialmente en España e Italia.

Sin duda, la crisis económica, social y política es determinante en la historia de los movimientos migratorios de ecuatorianos a los países europeos, sin embargo, estos procesos migratorios también se multiplican por las redes de familiares y amigos en el exterior, manteniéndose como una constante a lo largo de la historia de los movimientos migratorios, permitiendo su producción y reproducción como se afirmó en otro estudio ${ }^{6}$.

6 Ver Marisol Patiño y Blanca Pesantez: La migración internacional: relatada e interprelada por los jóvenes en los países de origen y de destino, en la revista italiana del CSER, pág. 345. 
Estas redes, cuyo tejido fue iniciado por los identificados como los "pioneros", se desarrollan, evolucionan y se multiplican. Sus protagonistas proveen información, preparan las condiciones laborales y habitacionales para otros inmigrantes que emigrarán posteriormente. Patricio Carpio $^{7}$ afirma que cuando estas redes se han consolidado se convierten en una "institución" por la cual los nuevos migrantes se integran al mercado de trabajo preestablecido, a "medios culturales trasladados", convirtiéndose estas redes en "enclaves culturales" de amigos y parientes $(1992,86)$.

\section{ALGUNAS CARACTERÍSTICAS SOCIODEMOGRÁFICAS DE LA POBLACIÓN ECUATORIANA INMIGRANTE EN FRANCIA}

Según la Cónsul de Ecuador en Francia existen actualmente registrados en la Embajada 1.700 ecuatorianos, sin embargo, estima que la población es mayor, supone que deben habitar en territorio francés aproximadamente 5.000 ecuatorianos.

"Sabemos que muchos están llegando pero no se inscriben por temor, posiblemente haya muchos, pienso que debe haber en total entre los que se han inscrito y los que no lo han hecho unos 5.000 ecuatorianos, aunque me han dicho que al sur están llegando muchos jóvenes sobre todo artesanos y músicos. También hay una población fluctuante que viaja por Holanda, Bélgica y Francia."

Cuando se le consultó a la Cónsul sobre las características socioeconómicas (edades, ocupaciones, ciudades de donde proceden) de la población ecuatoriana inmigrante, señaló lo siguiente:

"La mayoría son personas vinculadas al arte: músicos, escritores, pintores, también personas que se han casado con franceses, aunque últimamente hay mucha gente que está trabajando en limpieza, en las casas, en restorantes, como albañiles y otros trabajos que los franceses ya no les gusta hacer. Las edades de las personas que viven acá van entre 20 a 50 años. Según el Ministerio de Educación existen 400 ecuatorianos estudiando en Francia."

Al igual que en el resto de países de Europa y EEUU, como se dijo anteriormente, la población de inmigrantes ecuatorianos en Francia, aumentó sustancialmente a partir de la crisis económica, financiera y política que enfrenta nuestro país en los últimos años, como lo ratificó la Cónsul.

7 Sociólogo ecuatoriano, uno de los primeros en investigar sobre las redes de familiares de migrantes ecuatorianos. 
"A partir del salvataje bancario la gente que ha inmigrado a Francia ha aumentado, las mujeres están trabajando en las casas y otros como albañiles. La población que llega a Francia está aumentando considerablemente, antes recibiamos 20 pasaportes al mes, ahora 50".

Se le consultó a la Cónsul sobre la integración de esta población a la sociedad francesa y sobre las percepciones que considera tienen los franceses sobre los ecuatorianos, la respuesta fue la siguiente:

"El ecuatoriano en Francia tiene fama de ser decente y responsable. Las personas les cuesta integrarse acá sobre todo por el idioma, también tienen problemas al conseguir arriendo, acá los franceses son muy estrictos con las leyes no arriendan a las personas que no tienen papeles".

Los testimonios de tres personas, que como se indicó anteriormente viven muchos años en Francia, informantes claves, corroboraron la información respecto a que la población ecuatoriana ha aumentado en los últimos años y que tienen más dificultades para insertarse en la sociedad francesa.

"Antes había pocos ecuatorianos, ahora hay más, se llevan más entre ecuatorianos, pero a veces forman grupos cerrados, yo por mi trabajo debí relacionarme más con franceses, en general la gente elige lo más fácil, es decir, llevarse con otros latinos". Jaime.

"Los ecuatorianos, sobre todo los que han llegado últimamente, que son bastantes, quieren hacer lo mismo que hacian en Ecuador, pero acá la gente es más organizada". Edison.

"He escuchado que están llegando más ecuatorianos, sobre todo al sur de Francia". Alfredo.

Sobre los problemas que enfrenta esta población y sobre su regularización, las personas, informantes claves, nos señalaron lo siguiente:

"El año pasado repatriaron a muchos ecuatorianos por no tener papeles, 3 ó 4 al mes" "Mucha gente está llegando hipotecando todo lo poco que tienen allá" El principal problema es la desintegración familiar, la mayoria de las personas dejan a sus esposos o esposas e hijos y eso está provocando muchas consecuencias negativas para la familia". Testimonio de la Cónsul.

"Me parece que hay mucha población que está llegando de manera irregular, con los consecuentes problemas que eso conlleva, nadie les arrienda ni les da trabajo, los franceses son muy estrictos y temen no cumplir con la ley". Jaime. 


\section{IMAGINARIOS SOBRE LA MIGRACIÓN ¿SUEÑOS, UTOPÍA O FRUSTRACIÓN, ILUSIÓN O DESILUSIÓN, LO IDEAL VS. LO REAL?}

Los imaginarios sobre la migración son construcciones sociales que empiezan a ser elaboradas por la información que reciben los "potenciales" migrantes de sus familiares en el exterior, a esto se suma las imágenes seductoras del "sueño europeo" que forman parte de un tipo de representaciones sociales "míticas".

Esta representación social "mítica" concibe a los países del llamado primer mundo como los espacios territoriales donde las oportunidades de mejorar el nivel de vida se concretizan.

"Nos llega la información de allá y nos dicen que en Europa se ganan mejores sueldos que en nuestro país". Iván.

"Te hacen creer que en Europa se cumple tu sueño dorado de desarrollarte en el arte". Henry.

En el proceso de construcción de los imaginarios existe un antes y un después, lo que marca esta variación temporal es el hecho migratorio. En la primera fase de dicho proceso, los sujetos antes de emigrar ven lo imaginado como una realidad inminente o se diría que viven lo imaginado como lo real, es decir, relegan sus aspiraciones de realización personal en su país de origen para priorizar en su proyecto de vida la ilusión del viaje al exterior, consecuentemente, viven en función de esa proyección, situación que es representada como una realidad inminente cuando existe la presión de la cadena y/o redes de familiares.

Como se indicó anteriormente, lo imaginado al confrontarse con lo real se convierte en algunos casos en frustración o desilusión.

"Vine acá con la ilusión de estudiar y de trabajar, de encontrar las oportunidades que en nuestro país ya no encuentras". Juan.

"Siempre estuvo en mi mente la idea de venir a Francia, desde hace mucho tiempo organicé mi vida en función de este viaje". Paola.

En un segundo momento, en el país de destino, esas imágenes positivas y/o sueños se ubican en un espacio, que se podría llamar de "ensoñación", es decir, los recién llegados o inmigrantes, por un lado, deslumbrados por lo nuevo y por las posibilidades que ofrecen (a primera vista) los países europeos, tratan de forzar la realidad, o de extender el "sueño europeo" a pesar de haber despertado o aterrizado en una realidad que no corresponde a la valija de ilusiones que portaron desde los preparativos del viaje hasta su realización. 
"Como buena latina, pensaba que lo de fuera era mejor que lo nuestro, la tipica idealización. Después, al conocer el país desde una perspectiva de turista, era el país ideal: de gente honesta, de oportunidades, rico, etc. Pero una vez como residente el cuadro cambió; al implicarse en la vida laboral, social y cultural. En lo laboral en Francia se tiene muchos derechos inimaginables, en Ecuador vendrían a ser una utopia, por ejemplo, ayuda económica en caso de pérdida del empleo, la posibilidad de tener hijos y continuar en la vida laboral activa, servicio médico óptimo, etc. Sin embargo, como en todas partes, el sistema no es infalible ni perfecto, pero claramente muchísimo mas ventajoso que el de nuestro Ecuador. Helena.

Posteriormente, estas aspiraciones se desvanecen, en algunos casos, se pierde el interés por preservarlas y se convierten en imágenes negativas, evidenciadas en las dificultades que deben enfrentar al intentar integrarse en la sociedad receptora, con la consecuente exclusión y frustración que aquello conlleva; o cuando cotidianamente sienten que es difícil el acceso a las oportunidades que el país idealizado supuestamente les ofrecía.

"Imaginaba que en estos paises es más fácil conseguir trabajo, pero llegas acá y no es fácil, entonces vives frustrado". Henry.

"Cuando uno se prepara para venir a este pais viene con una imagen positiva de este país, pero llegas, te da una decepción porque todo lo que uno imagina sobre este país existe pero el acceso a todo eso no es fácil, primero porque hablas otro idioma y después por el individualismo, aqui uno aprende a vivir la soledad y hasta llegas a arrepentirte por haber venido, hay que recuperarse de ese estado que te puede durar dias o meses, hay gente que resiste y que se queda y otra que no lo resiste y se regresa". Martín.

En otros casos, las imágenes se mantienen aunque expresan algunos cambios, sobre todo los sujetos inmigrantes, cuando realizan interpretaciones sobre las relaciones sociales en los países de destino, consideran que las imágenes positivas se desdibujan cuando son evidentes las diferencias en las prácticas culturales y/o afectivas.

"Antes de venir a instalarme tenia más o menos esa imagen superficial: paisajes lindos, arquitectura diferente, buen vino y un París de Cortázar! Ahora lo veo todo diferente. Nada fue fácil, nada fue gratis, hubo mucho esfuerzo de por medio. La Francia sigue siendo un pais lindo, un pais muy rico, con una cultura maravillosa, pero es un pais a veces frio, donde te puedes llegar a sentir muy sola, donde tienes mucho que aprender si vienes de lejos, donde el tiempo pasa muy rápido y donde la gente se preocupa primero por si misma antes que por los demás". Paula. 
"Imaginaba que era un país más avanzado, civilizado, con más tecnologia. Ahora sé que es un país donde la gente es más cuadrada (estricta), con mucha disciplina, asi han conseguido este desarrollo y si no sigues su ritmo, te quedas al margen (excluido)". Juan.

Como se indicó anteriormente, las imágenes del país de destino son alimentadas por la información que reciben de los familiares, también migrantes, en otros países, principalmente en EEUU, y que conllevan una comparación entre los países que ofrecen estas oportunidades, con la consecuente diversificación de los lugares de destino y el surgimiento de las familias multinacionales sobre las que nos referiremos posteriormente.

"Tenia dos opciones: irme a EEUU donde vivía mi papá o venirme a Francia, mi papá me decia que en Francia la gente es más sana, más culta y que en EEUU habia más depravación, más drogas". Pablo.

"Yo tenía la idea de ir a EEUU porque allá vive parte de mi familia, pero decidí venir a Francia, a EEUU es más dificil y porque acá en Francia pensé que había más posibilidades de desarrollarme en el arte". Jaime.

Se puede observar en estas frases la imagen positiva que se mantiene de la migración como tal, cuando los inmigrantes anteriormente habitaban en otro país europeo, principalmente en España, a pesar de admitir la existencia de prácticas negativas en la primera sociedad de acogida, como decíamos antes, se produce una suerte de persistencia del sueño europeo, aunque para ello deba trasladarse a otro país como Francia, en el que debe enfrentar otro tipo de adversidades como la de no encontrar masivamente conciudadanos o la de hablar otro idioma.

"Antes de venir a Francia, mis hermanos y yo vivíamos en España y cuando íbamos a venir acá yo pensé que era igual que España, pero es diferente acá hay menos ecuatorianos". José.

Estas imágenes evidencian un discurso construido a partir de la expresión de otro tipo de relaciones familiares, las multinacionales, cuyos canales de comunicación y de construcción de significados requiere la revisión de los postulados teóricos respecto a la estructura familiar.

\section{VII. ¿APEGO O DESAPEGO A LO NACIONAL?: IMÁGENES SOBRE ECUADOR ANTES Y DESPUÉS DE INMIGRAR A FRANCIA}

Sucede lo contrario con las imágenes del país de origen, antes del hecho migratorio, las imágenes son negativas: hablan de un país que no 
ofrece oportunidades de realización personal, que no ofrece empleos o salarios dignos, un lugar donde hay mucha corrupción.

"En nuestro país hay mucha pobreza, te pagan una miseria, no valoran tu trabajo". Armando.

"Me cansé de la crisis de mi país, de tanta injusticia y corrupción por eso decidí venir a probar suerte acá". Pedro.

"En Ecuador te cierran las puertas, allá las posibilidades de desarrollarte son muy dificiles y hacer lo que te gusta, por ejemplo, en Ecuador no puedes vivir del arte". Juan.

Estas imágenes cambian al intentar insertarse en las sociedades de destino, comenzando así un proceso de idealización de su lugar de origen. Ante la desilusión que experimentan por no encontrar la concreción del "sueño europeo", al enfrentarse ante la realidad de un sistema excluyente, y si a esto se suma la añoranza de los familiares y amigos que permanecen en el país de origen, es de esperarse que estas imágenes se conviertan en positivas e ideales, como se puede observar en los siguientes testimonios:

"En Ecuador la situación está muy dificil, pero en Francia tampoco es fácil, ahora siento que me gusta mucho más Ecuador". Mario.

"En Ecuador te pagan una miseria, no valoran tu trabajo, por eso tienes que salir a buscar mejores días, pero acá tampoco es fácil y mi pais es mi país, extraño mis amigos, la comida, no me pierdo un partido de fútbol cuando juega mi país". Juan.

En algunos casos, principalmente los estudiantes, consideran que en el imaginario de los ecuatorianos existe una suerte de xenofilia, es decir, está presente en su discurso la imagen de las personas que estudian en el exterior como la de un sujeto con mayor reconocimiento social.

"En Ecuador se tiene la idea de que los títulos extranjeros son muy importantes, tener un título de una universidad francesa es bien visto, te abren las puertas. Te aprecian o te valoran más si has estudiado cine o literatura fuera del pais". Pablo.

"En Ecuador hay la tendencia a valorar más lo que viene del extranjero". Jaime.

\section{IMÁGENES SOBRE LA RELACIÓN CENTRO-PERIFERIA ¿EXCLUSIÓN O INCLUSIÓN?}

No es objeto de este estudio profundizar en el análisis de la migración internacional en el marco de las relaciones centro periferia o una reflexión sobre este hecho social en el marco de las teorías sobre el sis- 
tema mundial, sin embargo, es necesario mencionar que las imágenes de los sujetos investigados sobre las sociedades de destino provienen o se construyen a partir de las descripciones simbólicas de la relación entre los países del norte y sur, en las cuales se identifica a los países del "Norte" o llamados también del "Centro" como las sedes de la tecnología, la industria, o como los "países de las oportunidades"; imágenes que han sido alimentadas por los grupos de poder de los países de destino, cuando ha resultado conveniente para sus intereses, bajo un supuesto beneficio nacional económico o demográfico.

Los sujetos investigados identifican a Francia como el centro de la cultura y su país de origen como el ámbito subcultural, reproduciéndose en su discurso una visión de mundo en donde desde el centro se mira al resto, percepciones que fortalecen consciente o inconscientemente el poder de estos países y la exclusión de los países llamados de la "periferia".

"Europa es la cuna de la cultura, del mundo civilizado, en nuestro pais la gente es menos estudiada, por ejemplo, acá, los jóvenes además del francés saben por lo menos dos idiomas más". Pedro.

"Francia es un pais más adelantado que el nuestro, acá todo es más organizado, hay más riqueza, en Ecuador hay más pobreza". Henry.

Las percepciones sobre la relación centro-periferia también se reproducen al interior del país de origen, en donde los procesos de exclusión y discriminación son evidentes. Por ejemplo, se puede observar en el discurso etnocéntrico mestizo la subvaloración de la cultura indígena y de la producción local, que paradójicamente es más valorada por algunos sectores en los países de destino, como lo afirmaron todos los jóvenes indígenas (artesanos y/o artistas) entrevistados.

"Yo me siento extranjeramente ecuatoriano y así me siento no sólo ahora que vivo en Francia sino también cuando vivía en Ecuador, nosotros viviamos en el campo y cuando llegamos a la ciudad, la gente no nos trataba bien, aun en la ciudad en mi pais me sentía como extranjero". Luis.

"En Ecuador muy poco se venden muestras artesanias en cambio acá, sí aprecian lo que hacemos, pero acá tienen la imagen de que todos allá somos indigenas y es como una moda que todos quieren saber de nosotros los indios, compran nuestros productos porque estamos de moda". Manuel.

A través de la observación participante se pudo constatar como algunos de los grupos de artistas indígenas (otavaleños y salasacas, principalmente) empleaban en su vestuario parte del atuendo que emplean los grupos indígenas de EEUU. En las interpretaciones musicales se 
podía notar una suerte de híbrido musical entre los ritmos como el San Juanito y los cantos presentes en los ritos de los indígenas de este país norteamericano.

"Acá les gusta nuestra música, les gusta vernos con trajes de indios aunque sea mezclados con los trajes de los indios de EEUU, hay que vender una imagen". José.

La venta de esta imagen tiene un costo cultural que si bien es reconocida por estos indígenas, sin embargo, la relegan a un segundo plano porque lo prioritario es la lucha por la sobrevivencia y el interés principal es lograr la aceptación de la sociedad de destino, o mejor aún para cautivar a un mercado extranjero que supuestamente se deja seducir por lo "nativo".

\section{EL PUNTO DE LLEGADA: REPRESENTACIONES SOCIALES SOBRE LA INTEGRACIÓN EN LA SOCIEDAD FRANCESA}

\section{1. ¿Integrarse o "acostumbrarse"?}

Es interesante analizar como la representación social de integración está más ligada al concepto de "acostumbrarse". En reiteradas ocasiones los entrevistados emplearon este término para referirse a la asimilación de prácticas culturales de la sociedad francesa más que a definiciones derivadas de un proceso real de integración. Salvo en algunas excepciones, en casi todas las entrevistas, los jóvenes emplearon la frase "te acostumbras" en lugar de "te integras".

"La vida acá es muy agitada, la gente no tiene tiempo para nada, ni para estar en familia, es dificil, después te acostumbras". María.

"El nivel de vida es mejor acá, aunque cuesta mucho acostumbrarse a la disciplina del francés y a pagar impuestos por todo, pero también es mejor la educación, la seguridad social, etc.". Juan.

"Todavía no me acostumbro por el idioma y porque la gente no es como allá en Ecuador que somos más cariñosos". Armando.

En la mayoría de las entrevistas realizadas en Francia, los jóvenes afirmaban que entre las dificultades más importantes que debían enfrentar para integrarse son las relacionadas con el aprendizaje del idioma francés y la comprensión del sistema administrativo, legal y principalmente el sistema de rentas de este país, consideran que aún no existe una cultura tributaria en el país de origen. 
"No me enseño en este país porque se paga muchos impuestos, por todo debemos pagar impuestos, no me acostumbro, en nuestro país es diferente se pagan menos impuestos". José.

"Aqui si eres disciplinado y cumples con todo te va bien, te acostumbras, si no, no te va bien". Pablo.

En otro tipo de testimonios se puede observar como las representaciones sociales sobre la integración cambian, principalmente, en las personas que han logrado descifrar los códigos de funcionamiento de la sociedad francesa y que además han incorporado a sus prácticas, algunos de los "ritos" de la vida cotidiana de las grandes ciudades europeas, como el dominio de las rutas y del traslado en el metro o trenes (TGV) de alta velocidad, tan acelerados como el ritmo de vida de los franceses, que distan mucho de los ritos, ritmos y prácticas de la cultura andina.

"Al principio era dificil acostumbrarse al metro, conocer las rutas.

También los horarios de atención de los almacenes eran diferentes, después ya te acostumbras, pero al principio es dificil, te pierdes". Juan.

Las personas que han logrado integrarse a la sociedad francesa son precisamente quienes han contraído matrimonio o mantienen una relación afectiva con franceses o han adquirido el status de residente. Para ellos el sistema de protección de derechos de la sociedad francesa es efectivo, piensan que el sistema francés es muy estricto en el cumplimiento de la ley, que los pagos por los impuestos son muy elevados, sin embargo, piensan que gracias a esa disciplina indeleble, la educación, la seguridad social, la salud y, en general, el nivel de vida es mejor.

"Hoy me siento bien porque pienso que he adoptado a este pais y viceversa. Lo que me gusta de este país es el respeto a los derechos humanos, la cultura (arte, literatura, música, etc.)". Helena.

"Aqui se vive mejor, el sistema de salud, de seguridad social, la educación es mucho mejor que en nuestro pais". Henry.

Es interesante analizar las diferencias en las representaciones sociales sobre la integración entre los hombres y las mujeres. En el caso de los indígenas artesanos varones que antes de inmigrar a Francia vivían en España, definen a este país como un lugar donde el trabajo es lo importante, pero prefieren la sociedad española para vivir, piensan que la integración en España es más fácil porque hablan el mismo idioma, existe más población ecuatoriana y se sienten como en su país de origen.

Al contrario, las mujeres artesanas, definen a Francia como el país donde han encontraron mayor reconocimiento, aceptación y además el sistema de control y disciplina francesa ha obligado a sus parejas a 
disminuir la ingesta del alcohol y los problemas que se derivan de esta práctica de consumo más habitual y aceptada en España.

"No me enseño todavía en Francia, en España sí, hay más ecuatorianos, con ellos jugábamos fútbol, acá no conocemos a mucha gente, por eso yo me siento en España como en mi casa y en Francia es el lugar donde trabajo". Luis.

"Yo estoy contenta acá, sólo el idioma es lo dificil, pero repitiendo se aprende, cuando viviamos en España, mi marido se encontraba con los amigos, ya no salía a vender y se ponía a beber, acá no, porque está prohibido, los franceses son más estrictos y él se cuida más de beber". Rosa.

Lo que contribuye a una mejor inserción de las personas inmigrantes en la sociedad de destino es su regularización, situación que es mucho más difícil para los indígenas artesanos que inmigraron por razones de trabajo, que para los jóvenes artistas y/o estudiantes que en la mayoría de casos han regularizado su estadía en Francia como estudiantes.

"Empecé a acostumbrarme a vivir aquí y a estar más tranquila cuando tuve los papeles, eso me daba más seguridad y podía trabajar, tranquila". Rosa.

"Llegué con visa como estudiante. Los franceses cumplen la ley y controlan todo, es bien dificil que vivas acá, si no tienes papeles, sin papeles no te aceptan, ni para arrendarte un departamento". Luis.

"Es bien dificil que consigas trabajo aqui en Francia si no tienes ya un contrato de trabajo, acá no puedes venir a la aventura como en España o EEUU". Henry.

Las representaciones sociales de los jóvenes estudiantes y artistas difieren de las de los jóvenes indígenas artesanos, para ellos el arte es un camino o un canal que facilita su inserción en la sociedad francesa.

“A los franceses les gusta que hables francés, si sabes su idioma, te aceptan más fácilmente y si eres artista también, les llama la atención nuestra música y bailes". Juan.

"Me costó mucho adaptarme, pero me ayudó mucho saber el idioma, pero creo que te puedes comunicar más fácilmente a través del arte, e incluso te puede ayudar mucho para aprender el idioma. Por ejemplo, a mi me sirvió mucho ir al cine para aprender el francés". Martín.

"Lo que me ayudó mucho a adaptarme fue saber el francés, a estudiar y a trabajar en lo que me gusta que es hacer música". Pedro.

En los dos últimos testimonios el término para referirse a la integración es el de adaptación, en estos tres casos el común denominador era el dominio del idioma francés, sin duda, uno de los factores que facilita la integración de los jóvenes es el manejo del idioma. 


\section{X. ¿REDES FAMILIARES DE INMIGRANTES O NUEVAS ES- TRATEGIAS DE SUPERVIVENCIA DE LAS UNIDADES FA- MILIARES?}

En anteriores investigaciones se planteó como supuesto que los flujos migratorios se incrementan por la crisis económica que enfrenta Ecuador, lo que obliga a su población a buscar nuevas estrategias de sobrevivencia en el exterior, pero también por el sistema de redes de familiares y amigos que posibilitan que los procesos migratorios se produzcan y se reproduzcan, manteniéndose como una constante en la evolución histórica de dichos procesos, principalmente en la región del sur del país ${ }^{8}$.

Este planteamiento pudo ser corroborado con la información que se obtuvo en la presente investigación. Los jóvenes entrevistados afirmaron que inmigraron a Francia contando con el apoyo de familiares que residían antes en este país europeo y que, a su vez, ellos han facilitado y motivado la inmigración de sus hermanos menores.

"Antes de mí, estaba mi hermano mayor, después vine yo y después le trajimos a mi hermana menor, ahora ella también vive acá". Armando.

"Yo llegué acá porque mis primos y tíos viven acá, ellos me contaban sobre Francia y, bueno, quise venir a aprender el francés, a estudiar y trabajar". Martín.

"Estamos viviendo acá seis hermanos, tres casados y tres solteros, pero uno de ellos va y viene de España". Octavio.

En este último testimonio, al igual que en otros, se puede observar un nuevo tipo de estructura familiar multinacional, es decir, varios integrantes del grupo familiar están dispersos en diferentes países. Este tipo de relaciones familiares trasciende la usual relación binacional, padre o madre en el exterior y joven en el país de origen.

La mayoría de los entrevistados afirmaron tener al padre, a la madre o hermano viviendo en otro país, principalmente en EEUU y/o España, además de los que viven en el país de origen y del que obviamente habita en Francia.

"Mi padre vive en EEUU, yo vine acá y después mi hermano. Mi madre vive en España". Pedro.

"Uno de mis hermanos vive en España, mi padre está en EEUU, mi madre en Ecuador, y yo acá". Armando.

8 Al respecto se menciona el artículo de la autora de este estudio sobre El fenómeno social de la migración internacional: una lectura desde el sur del pais, en Globalización, migración y derechos humanos, Programa andino de DDHH, editor, pág. 146. 
Se ha resaltado en varios estudios la importancia que juegan las cadenas familiares en la información y asesoría que brindan a los "potenciales" inmigrantes en el país de destino, sobre la inserción en el mercado de trabajo, los lugares o ciudades donde habitar, etc. Sin embargo, muy poco se ha estudiado sobre el rol que juegan las redes de familiares en la inserción de los nuevos inmigrantes en dichas sociedades con diferentes características culturales.

Uno de los objetivos de la presente investigación fue precisamente conocer cuáles son las representaciones sociales de los jóvenes sobre las redes familiares y sobre cómo estas redes contribuyen o no en su proceso de inserción en los países de destino.

En el discurso de la mayoría de los jóvenes entrevistados se evidenció el rol que juegan los familiares en la comprensión de los códigos y funcionamiento de la sociedad francesa, así como en la orientación de las nuevas prácticas urbanas que deben incorporar a su vida cotidiana

"Al principio como todo era nuevo, era muy complicado, si no fuera porque mi hermano ya vivía acá, todo hubiese sido más dificil. Él me ayudó a conseguir trabajo, a estudiar francés, a entender cómo son los franceses". Pablo.

"Cuando recién llegué a Paris no sabia cómo funcionaba el metro, ahora ya sé cómo funciona todo acá, me sirvió mucho también la información y las explicaciones de mi familia que ya vivían acá antes". Manuel.

Además de las redes de familiares, en las entrevistas, se pudo conocer que los motivos para inmigrar a Francia son diversos, principalmente se puede observar las diferencias entre los motivos expresados por los indígenas artesanos y los jóvenes estudiantes o artistas.

"Vine para estudiar y para desarrollarme en lo que me gusta, que es la música". Henry.

"Vine porque mi padre es francés y mi madre es ecuatoriana, ellos piensan que es mejor el nivel de vida acá, por eso decidieron que nosotros debiamos estudiar acá". Jan.

"Se sale del país con un proyecto en mente, cada ser humano migrante tiene su propia historia, su propio motor que lo llevó a salir, sea por estudios, trabajo o por otros problemas incluso afectivos". Paula.

"Mi hermana tenía una madrina francesa que la trajo, en mi comunidad era dificil estudiar, el colegio estaba bien lejos, no estaba haciendo nada y ella me trajo acá". Manuel. 
En el caso de los jóvenes indígenas artesanos los motivos para emigrar se derivan precisamente de las estrategias de sobrevivencia familiar o como parte de las estrategias que sustentan la economía familiar.

"Vamos recorriendo las ferias por toda Francia, compras un libro en las tabaquerías en el que te dicen dónde y en quéfechas serán las ferias y vas reservando el puesto y sacando el permiso, pero no es fácil, es muy cansado tanto viaje y en cada lugar te piden permiso y papeles". Manuel.

"Venimos a Francia porque acá lo que vendemos es novedad, allá en España la gente ya ha comprado, ya no es novedoso, acá todavía a la gente le llaman la atención nuestras artesanías". Teresa.

"En España hay muchos otavaleños que venden las artesanias como nosotros y habia mucha competencia, por eso vinimos acá, para ganar un poquito más, porque allá habia muchos vendedores y cada vez habia que bajar el precio". Rosa.

Entre los motivos para inmigrar están presentes los que se derivan o son consecuencia de las políticas restrictivas de otros países europeos, principalmente de España. Así, por ejemplo, varios de los entrevistados, principalmente los indígenas artesanos, antes de inmigrar a Francia vivían en España, ellos también nos informaron que a partir del 11 de marzo esta población aumentó.

"Yo vivía con mi esposa en España, allá trabajábamos los dos vendiendo, pero se puso muy difícil allá, con lo de la visa y con lo que pasó el 11 de marzo, por eso nos vinimos acá". José.

\section{REPRESENTACIONES SOCIALES SOBRE SER INMIGRANTE EN FRANCIA Y SOBRE LA MIGRACIÓN INTERNACIONAL}

\section{1. ¿Autodefinirse como estudiante inmigrante o ser trabajador in- migrante?}

Si bien los motivos de los jóvenes artistas y/o estudiantes entrevistados para inmigrar a Francia no son por razones laborales, sin embargo, todos trabajaban. En algunos casos, en empleos precarios o eran explotados, sin embargo, muy pocos admitían esta condición de trabajador inmigrante y preferían definirse como inmigrante estudiante, no reconocían esta definición principalmente los jóvenes que provenían de una clase media empobrecida.

"Vine para estudiar pero también trabajé de mensajero, de conserje, en un restaurante, ganaba menos que los franceses, pero tenía lo suficiente para financiar mis estudios". Pablo. 
"Los cinco primeros años estudié y trabajé al mismo tiempo. Trabajé haciendo malabares, después cuidando niños y después en restaurantes". Juan.

"Quería estudiar francés, me presentaba en los trenes haciendo música con otros ecuatorianos, al principio era dificil porque no estaba acostumbrado a ese tipo de trabajo, pero después fue muy difícil porque no teníamos papeles". Armando.

¿A qué se debe esta resistencia a autodefinirse como trabajador inmigrante? Como se dijo anteriormente, persisten o se reproducen en el discurso de los jóvenes artistas y/o estudiantes entrevistados las representaciones sociales e imágenes legadas por los primeros grupos de inmigrantes ecuatorianos que llegaron a Francia, grupos de las elites económicas, académicas o artísticas del Ecuador para quienes ser inmigrante en Francia significa o simboliza status o prestigio social y que contrastan con las imágenes y representaciones sociales del ser migrante en EEUU y España, identificado como la persona que no tiene empleo, o que gana muy poco, o para quien viajar al exterior es la única forma de mejorar su capacidad adquisitiva o de poder acceder a bienes inmuebles como casas o vehículos lujosos, aunque para conseguirlo deban vivir precariamente en los países de destino.

En las entrevistas, salvo en algunas excepciones, los jóvenes inmigrantes se refirieron a la migración internacional brevemente, sin embargo, fueron enfáticos en señalar los tipos de migración, significaciones en las que se establece la mencionada diferenciación entre los inmigrantes trabajadores y los estudiantes y/o artistas.

"La migración para mí significa trasladarme de un lugar a otro por diferentes motivos culturales, artísticos o económicos". Jaime.

"Hay dos tipos de migración, la que es por motivos de trabajo y los que emigran por otras razones. Yo emigré para prepararme más en el arte". Pedro.

Se elabora y reelabora un discurso construido a partir de la diferenciación entre el ser migrante estudiante/artista en Francia y el inmigrante trabajador, representaciones sociales construidas sobre la base de las imágenes del "típico migrante", como se dijo anteriormente, el que inmigra a otros países como EEUU, España o Italia a vender su fuerza de trabajo. Estas significaciones negativas o peyorativas están presentes de manera consciente o inconscientemente en quienes se autodefinen como los "otros", los que no provienen de estos sectores explotados.

"Yo no soy el típico migrante como el que va a trabajar y a ser explotado en España”. Henry. 
"Acá a Francia, se viene a estudiar, a cultivarse, allá los que van a EEUU, España o Italia van a sacarse el aire (sacrificarse), a vivir hacinados en cuartos para ahorrar y construirse esas casas grandes". Pedro.

Es necesario indicar que todos los entrevistados trabajan, aún los que estudian, sin embargo, a muchos de ellos les costaba admitir que debían trabajar para financiar sus estudios.Esto lo diferencia de las primeras generaciones de ecuatorianos inmigrantes en Francia, quienes provenían de sectores vinculados a estratos socioeconómicos altos y que podían financiar los estudios de sus hijos en Francia?.

\section{EL DESENLACE: REPRESENTACIONES SOCIALES SO- BRE EL RETORNO ¿SER DE AQUÍ O DE ALLÁ?}

A medida que se insertaron en la sociedad francesa, dominaron el idioma, establecieron relaciones sociales o afectivas con los franceses la posibilidad del retorno definitivo a Ecuador es más lejana y a esto se suma la comparación que establecen entre los costos y beneficios que ofrecen las dos sociedades de origen y de destino.

"Al principio pensaba regresar, pero cuando ves las ventajas de vivir acá, porque es mejor el nivel de vida, la educación, el trabajo es mejor pagado que en Ecuador, ya piensas en quedarte”. Juan.

"Antes no sabiamos qué hacer si quedarnos o regresar, pero ahora pensamos quedarnos porque nos está yendo mejor, conocemos más gente, hablamos mejor el francés y en el trabajo nos va bien". Luis.

El retorno es relegado a un segundo plano cuando reciben información de sus familiares y amigos en Ecuador quienes se encargan de desdibujar la imagen ideal del país de origen, imágenes que se tornaron más dramáticas a partir de la crisis económica y política que enfrenta este país.

"Pensábamos regresar con mi hermano, pero cuando nos cuentan cómo está la situación en Ecuador no sabemos qué hacer, si regresar o no definitivamente”. Armando.

"Para qué regresar a Ecuador. Ahora menos, con tanto problema y tanta crisis. Pienso que es mejor quedarse aquí". Pedro.

Las nuevas prácticas y relaciones sociales aprendidas y establecidas cotidianamente por los jóvenes, a pesar de las diferencias culturales e idiomáticas de la sociedad francesa, como se dijo anteriormente, evidencian el poco interés por retornar definitivamente a Ecuador, sin em-

9 No sucedía lo mismo con los indígenas quienes todos trabajaban y ninguno estudiaba. 
bargo, se pudo identificar algunas frases que nos revelan un sentir y un actuar que, como dicen los jóvenes investigados, los hacen "ni de aquí ni de allá".

"Hablo mejor el francés, entiendo más a los franceses, me he acostumbrado a su estilo de vida, pero no soy ni de aquí ni de allá". Armando.

Es necesario indicar que existen diferencias entre los jóvenes estudiantes y los jóvenes indígenas o artesanos, en el primer caso, como se dijo anteriormente, la posibilidad del retorno definitivo es lejana, en el caso de los indígenas ellos aún sienten que el apego a su país de origen está vigente, sin embargo, es evidente una posición ambigua en su discurso, para ellos su situación ha mejorado al inmigrar a Francia, pero los lazos que mantienen con Ecuador persisten y les atrae la posibilidad del regreso, aunque no precisan cuándo será ese retorno definitivo.

"Salimos de nuestro país porque allá es más dificil, hay muchos problemas, salimos para hacer alguna cosita (dinero), pero extrañamos a nuestra gente, no pensamos todavia en regresar definitivamente".

Teresa.

En el caso de los jóvenes indígenas que tienen su pareja en Ecuador la posibilidad de retorno es más clara e inmediata, a pesar de que su situación económica es mejor en Francia, en este caso los vínculos familiares son más fuertes que la posibilidad de permanecer por más tiempo en este país europeo.

"Acá nos tratan mejor, valoran nuestras artesanias, pero allá está mi esposa e hijo y por eso pienso que debo regresar, los dos somos jóvenes y nos extrañamos". Armando.

\section{PERCEPCIONES A PARTIR DE SU INSERCIÓN EN LA SO- CIEDAD RECEPTORA}

\section{1. ¿Quiénes son los "otros", los franceses?}

En el tema referido a la integración se conoció sobre las representaciones sociales de los jóvenes ecuatorianos entrevistados sobre el sistema francés, interesa ahora precisar sobre cuál es su percepción sobre los franceses.

Las percepciones varían también al igual que las representaciones sociales a medida que avanza el proceso de inserción en la sociedad francesa. La primeras impresiones o las percepciones "a primera vista", como dicen los jóvenes, son atrayentes y son alimentadas por la curiosidad de conocer al "otro" o al "diferente", como ellos lo identifican. 
"Al principio, cuando uno llega a otro pais, quiere conocer gente diferente, los que son de acá". Juan.

"A simple vista, la mujer francesa es atrayente, a mi me gusta mucho cómo hablan". Armando.

Esta percepción o atracción por el otro o por la diferencia hace que, en algunos casos, como estrategia para insertarse en la sociedad francesa, los jóvenes (principalmente los estudiantes o artistas) opten por integrarse a los círculos sociales intelectuales o artísticos franceses, sin embargo, a medida que consiguen descifrar sus códigos y formas de actuar y perciben que las diferencias los distancian, optan por otro tipo de grupos de referencia.

"Al principio, atraído por esta percepción positiva del francés intelectual, todos mis amigos eran franceses. Ahora la mayoria de mis amigos son latinoamericanos, ecuatorianos y colombianos".

En otros testimonios, desde un inicio, los grupos de referencia, a los que se integran con mayor facilidad los jóvenes inmigrantes, lo constituyen las comunidades de inmigrantes ecuatorianas y/o latinas.

"Los ecuatorianos nos encontramos, jugamos fútbol, nos llevamos mejor entre nosotros o con otros latinos que hablan nuestro mismo idioma, hacemos bromas, entendemos los chistes. Los franceses no entienden nuestras bromas". Armando.

"Me llevo más con ecuatorianos y otras mexicanas o latinas, nos entendemos más, hablamos el mismo idioma, o, aunque no hablen, si son latinos, son nuestros hermanos. Por ejemplo, con los brasileños, aunque no hablan nuestro idioma, pero, como son latinos, nos llevamos bien, porque nosotros los latinos somos más cariñosos, los franceses son más fríos, menos expresivos". María.

"A la base, la comunidad latina fue mi primer cobijo, ya que conoci a mis amigos de la universidad donde todos estudiábamos el francés. Luego al trabajar me fui haciendo de amigos franceses y otros amigos latinos. Asi que diria un $60 \%$ de amigos latinos contra un $40 \%$ de franceses".

En los testimonios aparece nuevamente el idioma como una limitación para entablar relaciones más profundas o cercanas con los franceses. Una vez superada esta dificultad las relaciones y comunicación obviamente mejoran.

"Es dificil llegar a tener una conversación más profunda con ellos porque no hablan tu mismo idioma". Martín.

"Los franceses son dificiles de intimar, pero cuando los conoces bien ellos son amigos incondicionales". Jaime. 
Además de las diferencias idiomáticas, las dificultades más importantes que deben enfrentar los inmigrantes ecuatorianos para consolidar las relaciones con los franceses son las que se derivan de las diferencias en las prácticas culturales.

"Acá las relaciones son más frías, en Ecuador nosotros contamos con la familia, los amigos. Acá, cada quien vela por lo suyo". María.

"Acá sobreprotegen a los niños y jóvenes. Pareciera que tienen de todo, pero algo les falta, por eso se deprimen. Acá los jóvenes se deprimen mucho". José.

"Los franceses aunque tienen dinero se quejan, se quejan de pequeñeces. No imagino uno de ellos en la selva o creciendo en las condiciones como nosotros crecemos allá". Hernán.

Sobre las percepciones positivas que tienen sobre los franceses, los jóvenes entrevistados indicaron que en general las cualidades, a simple vista, de los franceses es que son disciplinados y sinceros.

"Mi percepción positiva sobre los franceses es la franqueza para decir las cosas que no les parece o gusta, cosa que difiere de mi país en donde se oculta lo malo o se miente al respecto y hablamos sólo de lo bueno". Helena.

"Los franceses son sinceros, si pueden ayudarte te dicen si y si no es asi no andan con rodeos como nosotros, no se preocupan por quedar bien, también son disciplinados". Pedro.

Es necesario indicar que en las entrevistas a los sujetos investigados no se pudo observar frases que develen una percepción de los franceses como xenófobos, salvo en los dos siguientes testimonios:

"Lo que no me gusta es el miedo que tienen algunos franceses a los extranjeros". Helena.

"Algunos, no todos los franceses, principalmente los que no conocen sobre otras culturas tienen miedo de la gente extranjera que ingresa a su pais". Pedro.

\subsection{Sobre cómo son percibidos por el otro}

Sobre las percepciones que ellos consideran que los franceses tienen de los ecuatorianos se identifican las míticas y las estereotipadas positivas o negativas. Estas percepciones varían entre los jóvenes artistas y/o estudiantes y las de los indígenas.

"Creen que somos machistas". Henry.

"Que somos decentes y trabajadoras". María.

"Hay muchos estereotipos por los que nos juzgan a todos". Jaime. 
En el caso de los indígenas, ellos consideran que los franceses tienen una percepción positiva de la población indígena, sin embargo, no dejan de ser vistos como un grupo étnico "exótico".

"Los franceses nos ven como indios exóticos". Luis.

"Han oído de los incas y piensan que somos sus descendientes". Octavio.

"Cuando nos ven en la calle cantando o vendiendo las artesanías, les llama la atención nuestra música, se acercan a escucharnos, creo que les atrae que seamos indios". Manuel.

Se identificaron algunas discrepancias sobre las percepciones que tienen sobre otros ecuatorianos inmigrantes en Francia, principalmente sobre la población inmigrante que ha llegado en los últimos años.

"Algunos jóvenes ecuatorianos que vienen por razones económicas les es más dificil integrarse al sistema francés, pero para otros es más fácil porque a través del arte es más fácil integrarte". Martín.

En este último testimonio nuevamente aparece la diferenciación entre las percepciones de los inmigrantes por motivos laborales y los estudiantes.

Sobre las percepciones que tienen sobre inmigrantes de otras nacionalidades, especialmente sobre los marroquíes y argelinos, grupos de inmigrantes de los más numerosos en Francia, se menciona lo siguiente.

"Los marroquies son más difíciles de comprender, no son muy queridos por los franceses porque tienen una cultura opuesta a la suya". Pablo.

\section{CONCLUSIONES}

Las imágenes y representaciones sociales sobre el ser inmigrante en Francia, construidas históricamente y legadas consciente o inconscientemente a las nuevas generaciones, están presentes en el discurso de los jóvenes entrevistados, principalmente de los que estudian. En su mayoría, a pesar de tener trabajos precarios y de pertenecer a sectores populares o a una clase media empobrecida, en su discurso persiste la imagen presente en la memoria colectiva sobre la migración a Francia como símbolo de status y prestigio académico, lo que provoca en ellos consciente o inconscientemente, un rechazo a ser identificado como el "típico migrante", el que ha inmigrado en búsqueda de empleo o por lo posibilidad de acceder a mejores salarios, auto-diferenciándose de los "otros", los que emigran a EEUU, España o Italia. 
Si bien la mayoría de los jóvenes estudiantes entrevistados se niegan a ser comparados con los otros migrantes (los que lo hacen por razones económicas), sin embargo, ninguno de ellos pertenece a sectores con los recursos económicos necesarios para sostener o financiar los estudios, situación que evidencia el empobrecimiento de la clase media, que, a diferencia de épocas pasadas, podía financiar los estudios de sus hijos en Francia. Posteriormente estos jóvenes se ven obligados a insertarse al mercado de trabajo, accediendo a trabajos precarios,

El común denominador de todos los jóvenes entrevistados es que inmigraron como parte de una cadena migratoria en la que sus predecesores son los hermanos o hermanas mayores, confirmándose la tesis de que estas cadenas y/o redes familiares constituyen un factor determinante en la producción y reproducción de los procesos migratorios.

La migración es significada e interpretada por los jóvenes inmigrantes como la posibilidad de mejorar las condiciones de vida y de realización personal, inspiradas en un imaginario colectivo construido a partir del "sueño europeo", imágenes que cambian al confrontarlas con la realidad y con su condición de ser inmigrante y se convierten, más bien, en la utopía de construir en el exterior lo que no es posible conseguir en el país de origen, especialmente en el caso de los jóvenes inmigrantes que anteriormente habitaban en otro país europeo (España, principalmente). A pesar de que admiten que existen prácticas y códigos culturales difíciles de comprender en estas sociedades, persiste su interés por alcanzar sus aspiraciones, aunque para ello deban trasladarse a otro sistema de vida como el francés, en donde deben enfrentar otro tipo de adversidades como la de hablar otro idioma o la de no encontrar masivamente conciudadanos, como sucede en España o Italia.

Se pudo identificar algunas contradicciones entre las prácticas y el discurso de los jóvenes, por un lado, cuentan sobre las dificultades para integrarse, entender la cultura francesa y para aprender el idioma, sin embargo, en sus prácticas cotidianas, se puede observar la asimilación de ciertos "ritos urbanos" que corresponden a la cultura francesa.

Los jóvenes, que en su país de origen eran considerados como un común ciudadano, se convierten en el país de destino en un inmigrante más, con todas las implicaciones que aquello implica, buscan protegerse de la desilusión que surge al confrontar lo imaginado con lo real y, por otro lado, para eludir estigmatizaciones (en el país de destino) y de que lo identifiquen como un ser fracasado (en el país de origen) y luchan por preservar la concreción de sus ideales y de su realización personal.

En el imaginario de los jóvenes inmigrantes se evidencia un discurso construido a partir de la expresión de un nuevo tipo de relaciones fa- 
miliares, las multinacionales, cuyos canales de comunicación, de construcción de significados e interpretaciones requiere la revisión de los postulados teóricos respecto a las unidades familiares.

A medida que los jóvenes comparan las ventajas de vivir en Francia con la situación y las pocas posibilidades que ofrece la sociedad ecuatoriana, la posibilidad del retorno definitivo a su país de origen es más lejana.

\section{BIBLIOGRAFÍA}

ALONSO, L.E. (1998): La mirada cualitativa en sociologia, editorial Fundamentos, primera edición, pg. 35-126.

ALTAMIRANO, T. (2004): Perú y Ecuador, nuevos paises de emigración, en Globalización, Migración y DDHH, Programa de DDHH de la Universidad Andina, editor. Quito, Ecuador. pg $237-252$

BERICAT, E. (1998): La integración de los métodos cuantitativo y cualitativo en la investigación social, editorial Ariel, primera edición, Barcelona, 37-85; 147-169:

CARPIO, P. (1992): Entre pueblos y metrópolis, editorial Abya Yala, Quito, Ecuador.

COHEN, J.(1987): Teoria de la estructuración y praxis social, en La teoría social, hoy de Giddens A. y otros, Estados Unidos.

DOLLAR J.: (1986) Criterios para una historia de vida, en La Historia de vida, CEAL.

FRANÇOIS, L. (2000): "La descripción ethnographique" ediciones Nathan/HER, París, Francia.

GALLORO, P. y otros (2004): Processus d'Aculturation et Relations Interculturelles, rapport intermédiaire de recherche, FASILD, UFR Sciences Humaines et Arts, Université de Metz, Metz, Francia.

GALLART, M.A. y otros (1992): Métodos Cualitativos II, la práctica de la Investigación. Centro Editor de América Latina, Buenos Aires, Argentina.

GALTUNG, J. (1995): Investigaciones teóricas, editorial Tecnos, primera edición 11-223.

GOICOCHEA, A. (2003): Los imaginarios migratorios, el caso ecuatoriano, editorial Abya-Yala, Universidad Andina Simón Bolivar, Quito, Ecuador.

HELLER, A. (1972): Individuo y comunidad ¿contraposición real o aparente?, en Historia y Vida cotidiana, aportación a la sociología socialista, Ediciones Grigalbo, México, pp 97-121.

HERITAGE, J. (1987): Etnometodología, en La Teoria Social hoy, de Giddens A y otros, Estados Unidos, pp 55-72

JOKISH, B. (2001): «Desde New York a Madrid: tendencias en la migración ecuatoriana», en la revista Ecuador Debate, ediciones CAAP, Quito, Ecuador, pp. 59-83.

KYLE, D. (2001): «La diáspora del comercio otavaleño: capital social y empresa transnacional», en Fugas Migratorias, revista Ecuador Debate, ediciones CAAP, Quito, Ecuador, pp. 84110 .

PATIÑO, M. (2004): «El fenómeno social de la migración internacional: una lectura desde el sur del país», en Globalización, migración y derechos humanos, Programa andino de DDHH, editor, Universidad Andina, Quito, Ecuador.

PATIÑO, M. y PESANTEZ, B. (2004): La migración internacional: relatada e interpretada por los jóvenes en el país de origen y de destino, revista del Centro Studi Emigrazione, Roma, Italia, pg. 341-357. 
PEDONE, C. (2002): Las representaciones sociales en torno a la inmigración ecuatoriana a España, revista ICONOS, FLACSO, No 14, Quito, Ecuador.

PENEF, J. (1990): La méthode Biographique, de l'école de Chicago à la histoire orale, Armand Colin editeur, París.

PONCE, F. (2003): «La libre circulación de personas: Desafío para el Derecho Internacional e indicador del desarrollo nacional», en Poblaciones humanas en movimiento, un reto para muestra sociedad. Revista Fe y Justicia. Número 9. Quito, Ecuador, pàgs. 37-53

PORZECANSKI, T. (1988): La Investigación social cualitativa, bases teóricas y metodológicas, Cuadernos CLAEH, Montevideo, Uruguay.

PUJADAS MUÑOZ, J.J. (1992). El método biográfico: el uso de las historias de vida en ciencias sociales, Centro de investigaciones sociológicas, Madrid, España.

RAMIREZ, F. y GOICOCHEA, A. (2002): Se fue, ¿a volver? Imaginarios, familia y redes sociales en al migración ecuatoriana a España (1997-2000), revista ICONOS, FLACSO, No 14, Quito, Ecuador.

ROTIER, N. (1989): La vida cotidiana, aspectos objetivos y subjetivos, CELATS, Módulos del curso de educación a distancia, Lima, Perú.

RUIZ, J.I. (1996): Metodología de la.Investigación Cualitativa, Universidad de Deusto, Bilbao, España.

SALTAMACCHIA, H. (1992): La historia de vida: reflexiones a partir de una experiencia de investigación, ediciones Cijup, Buenos Aires Argentina, Primera edición.

SANTA MARIA, E. (2002): Inmigración y barbarie. La construcción social y politica del inmigrante como amenaza, en Sociología de las migraciones, PAPERS, revista de sociología, Univeritat Autónoma de Barcelona, Server de publicaciones, 2002, pp. 59-75.

SILVA, A. (1992): Imaginarios urbanos, Tercer mundo editores, segunda edición, Bogotá, Colombia, 1992.

TAYLOR, S.J y BOGDAN, R. (1998): Introducción a los métodos cualitativos de investigación, ediciones Paidós, Barcelona España, cuarta reimpresión, pg. 15-185.

WOLF, M. (1988): Sociología de la vida cotidiana, ediciones Cátedra, segunda edición, Madrid España.

YAÑEZ COSIO, C. (1998): Representaciones y conceptos estructurantes, un aporte al método, editorial Abya-Yala, Quito, Ecuador, segunda edición, pg: 5-57 